\title{
OS CUIDADOS COM A DOENÇA FALCIFORME NAS AULAS DE EDUCAÇÃO FÍSICA ESCOLAR: O CONHECIMENTO DOS PROFESSORES SOBRE O ASSUNTO
}

\author{
$\underline{\text { Raiotelma Lopes Silva }}^{1}$; Lea Barbetta Pereira da Silva ${ }^{2}$
}

1. Bolsista PROBIC/UEFS, Graduanda em Licenciatura em Educação Física, Universidade Estadual de Feira de Santana, e-mail: telminha.lsiva@gmail.com

2. Orientadora, Departamento de Saúde, Universidade Estadual de Feira de Santana, email: barbetta@uefs.br

PALAVRAS- CHAVE: doença falciforme, educação física escolar, professores

\section{INTRODUÇÃO}

A doença falciforme (DF) é uma enfermidade hematológica de caráter hereditária, genética e crônica. Decorre através da anormalidade de uma proteína presente nas hemácias, a anemia hemolítica de herança autossômica recessiva, que ocorre devido a uma mutação da posição 6 do gene da globina beta da hemoglobina $(\mathrm{Hb})$. Este local onde ocorre a mutação propicia a substituição do ácido glutâmico pelo aminoácido valina, induzindo a produção de uma hemoglobina anormal (FERNANDES et al., 2002) .

A DF é considerada um grande problema de saúde pública, por conta do seu alto índice de casos no Brasil e no mundo. A Bahia possui a maior população negra do Brasil, especialmente na capital e na região do recôncavo, locais próximos à Feira de Santana. Estudo realizado por Alves (2012) mapeou a DF nessa região e mostrou que a prevalência foi de $0.04 \%$ ou 4 casos/ 10.000 habitantes. A maior ocorrência e prevalência foram para as pessoas pretas e pardas, com baixa escolaridade e baixa renda, fatores que influenciam diretamente a evolução clínica da doença, pois terão reflexo na alimentação, assistência médica, moradia precária, transporte, condições higiênico-sanitárias e educação.

A maioria dos sinais e sintomas presentes no quadro clínico dos indivíduos com DF tem como determinante a ocorrência de vaso-oclusões, principalmente em pequenos vasos (FELIX et al., 2010).

Crises de dor, úlceras de membros inferiores, síndrome torácica aguda (STA), seqüestro esplênico, priaprismo, necrose asséptica do fêmur, acidente vascular encefálico (AVE), retinopatia, insuficiência renal crônica, entre outros sintomas são descritos como os principais acometimentos da doença (FELIX et al., 2010). No entanto, devido às manifestações clínicas ocasionadas pela doença, que resultam em hospitalizações freqüentes, indivíduos que apresentam a DF, tem sua vida comprometida, o que para crianças e adolescentes, acabam interferindo no desempenho escolar do aluno.

A Associação Baiana das Pessoas com Doença Falciforme (ABDFAL) cita como fundamental o conhecimento da escola sobre as particularidades referentes ao crescimento e desenvolvimento da criança com DF (ABADFAL, 2013), como a ingestão freqüente de líquidos, a ida ao banheiro, temperatura, informações básicas que a comunidade escolar deve saber, para melhor compreensão do comportamento do aluno.

Sobre o processo de inserção do aluno com a DF no ambiente escolar, Maia et al., (2013) dizem:

As crianças com anemia falciforme devem ser matriculadas na escola tal como qualquer outra criança, a menos que existam razões específicas. É importante que os pais notifiquem a condição clinica de seus filhos ao 
professor e diretor da escola e os estimulem sempre a estudar e permanecer na escola, apesar das intercorrências que possam sobrevir.

A importância dos pais no processo de matrícula notificarem a instituição sobre a doença do aluno, informações essas que são importantes, para que no momento de emergência do mesmo, a escola saiba reagir diante da situação, dê apoio nos momentos difíceis, como várias internações que o sujeito com a DF poderá enfrentar, que conseqüentemente afetará o rendimento escolar. A compreensão de professores é fundamental nesse processo, oportunizando possibilidades de tarefas extra-escolares, fazendo com que o estudante não perca os assuntos trabalhados em classe.

Dentro desse contexto escolar, uma disciplina curricular que desperta preocupação por suas características, é a Educação Física. Segundo MAIA et al. (2013), "O professor de Educação Física tem que estar informado de que o aluno com doença falciforme deve evitar esforços físicos exaustivos, respeitando seus limites e a necessidade de manter-se hidratado durante a prática de exercícios". Sendo assim, é de fundamental importância que o professor de Educação Física tenha conhecimentos a cerca da DF, para que em suas aulas práticas, ele saiba adapta-las para que todos participem sem que ocasione alguma intercorrência, principalmente aos alunos adoecidos.

A ABADFAL (2013) recomenda a participação do estudante com a DF, nas aulas práticas de Educação Física, pois além de trazer benefícios a saúde há interação social entre os colegas. Interação essa, muito positiva para a melhoria da qualidade de vida desses sujeitos.

Apesar das recomendações acerca dos possíveis benefícios da participação dos alunos com DF nas aulas de Educação Física escolar, a questão norteadora do presente estudo é: qual o conhecimento dos professores de Educação Física sobre a DF das escolas públicas de Feira de Santana?

O objetivo do presente estudo foi identificar qual o conhecimento dos professores de Educação Física escolar da rede pública de ensino de Feira de Santana sobre os cuidados com a doença falciforme.

\section{MATERIAIS E MÉTODOS}

Foi feita uma pesquisa de campo, de corte transversal, com abordagem quantitativa, que de acordo com Falcão \& Règnier (2000) abrange um conjunto de procedimentos, técnicas e algoritmos destinados a auxiliar o pesquisador a extrair de seus dados subsídios para responder à pergunta de investigação de seu trabalho.

\section{Instrumentos de coleta de dados}

1- TERMO DE CONSENTIMENTO INSTITUCIONAL: documento que objetivou obter o consentimento institucional dos diretores de cada escola para a realização da pesquisa;

2- TERMO DE CONSENTIMENTO LIVRE E ESCLARECIDO (TCLE): documento apresentado à cada sujeito participante da pesquisa (professores e estudantes de educação física) a fim de obter o consentimento para a coleta de dados.

3- QUESTIONÁRIO AUTO-APLICADO: instrumento elaborado a fim de obter dados sobre o conhecimento dos professores de educação física acerca dos cuidados a serem tomados com alunos com DF e como tem foi o planejamento e execução das aulas considerando a presença desses alunos. 


\section{Procedimento para coleta de dados}

O estudo foi realizado no município de Feira de Santana/BA, abrangendo as escolas da rede pública de ensino. Inicialmente foi feito contato com a Secretaria Municipal e Estadual de Educação do município a fim de se obter a listagem das escolas pertencentes à rede pública de ensino do município. Após essa etapa foi realizada visita às escolas objetivando o consentimento dos diretores, através de um Termo de Consentimento Institucional para que a bolsista pudesse aplicar seu instrumento de coleta de dados com os professores de educação física das escolas. Também foi apresentado o Termo de Consentimento Livre e Esclarecido ao participante, informando sobre a pesquisa e informando que todos teriam total liberdade de não completar o questionário caso se sentissem constrangidos. Após o consentimento institucional, a pesquisadora fez visitas previamente agendadas às escolas para a aplicação do instrumento de pesquisa junto aos professores de Educação Física.

\section{RESULTADOS E DISCUSSÃO}

O estudo foi realizado no município de Feira de Santana/BA, abrangendo as escolas da rede pública de ensino localizadas nos bairros Tomba, Campo Limpo, Humildes, Jaíba e Matinha, que de acordo com estudo realizado por Alves (2012) foram as localidades com maiores frequiência de casos de DF do município.

Foram visitadas 17 escolas de educação básica dos bairros acima citados sendo 12 da rede estadual e cinco da rede municipal de ensino.

Participaram voluntariamente da pesquisa 35 professores de Educação Física, sendo 42,9\% do gênero feminino e 57,1\% masculino, média de idade de 38,1 \pm 11,6 anos.

Com relação à formação, a Tabela 1 demonstra que a maior parte dos professores de Educação Física que atuavam nas escolas públicas investigadas possuía graduação completa, sendo que $80 \%$ desses sujeitos estudaram em instituição de ensino superior pública.

Tabela1. Formação profissional de professores de Educação Física das escolas públicas de Feira de Santana- 2017.

\begin{tabular}{lcc}
\hline Nível de formação & $\mathbf{n}$ & \% \\
\hline Em processo de graduação & 9 & 25,7 \\
Graduado & 5 & 14,3 \\
Pós- graduado & 19 & 54,3 \\
Provisionado & 1 & 2,9 \\
\hline
\end{tabular}

Foi investigado se nas escolas existia algum tipo de ficha ou registro contendo informações sobre a saúde dos alunos e 68,6\% dos professores responderam que não, evidenciando que na maioria das escolas a equipe de trabalho desconhece condições que podem gerar algum tipo de situação que mereça acompanhamento diferenciado, especialmente nas aulas de Educação Física.

Sobre o conhecimento acerca da DF, 88,6\% dos professores registraram conhecer a doença, no entanto, a maioria $65,7 \%$ não obteve esse conhecimento durante o curso de graduação. Embora conhecessem a doença, apenas 2,9\% dos sujeitos pesquisados relataram esclarecimento sobre os riscos associados à doença, o que gerou insegurança em $68,6 \%$ dos professores quando questionados sobre a inclusão desses alunos em suas aulas de Educação Física.

Outro registro importante do presente estudo foi que $17,1 \%$ dos professores registraram a presença de alunos com DF em suas aulas e 8,6\% relataram que os mesmos não participavam das atividades por complicações da doença. Ao serem questionados sobre quais cuidados teriam com esses alunos em suas aulas, $28,6 \%$ responderam que exigiriam um relatório médico com liberação para as aulas práticas para que pudessem adaptar as 
atividades, controlar a intensidade dos exercícios físicos, além de acompanhar a alimentação e medicação dos alunos.

\section{CONSIDERAÇÕES FINAIS}

No presente estudo, pudemos perceber a escassez de informações sobre a DF na área de Educação Física. Apesar dos professores investigados conhecerem a doença, a maioria não sabia informações como, fisiopatologia, tratamento, sinais e sintomas e seus conhecimentos foram insuficientes para garantir segurança nos cuidados com os alunos com DF em suas aulas práticas. Nos cursos de graduação, poucos ouviram falar sobre a doença e as escolas não tinham nenhum tipo de ficha contendo informações dos alunos sobre algum problema de saúde.

A DF se mostrou invisibilizada na escola, especialmente na sub-área da Educação Física, espaço que deveria ser de acolhimento e inclusão de crianças e jovens adoecidos.

\section{REFERENCIAS}

ALVES, José, R. C. Aspectos epidemiológicos da doença falciforme e sua distribuição espacial em Feira de Santana no ano de 2010 a 2011 . Universidade Estadual de Feira de Santana, 2012.

Associação Baiana das Pessoas com Doença Falciforme - ABADFAL. Prefeitura de Salvador. Secretaria Municipal de Saúde de Salvador. Doença falciforme: a importância da escola. [Citado em 2013 jan 02]. Disponível em: http://www.saude.salvador.

FALCÃO, J. T. da R.; RÉGNIER, J. Sobre os métodos quantitativos na pesquisa em ciências humanas: riscos e benefícios para o pesquisador. Revista Brasileira de Estudos Pedagógicos, Brasília, v. 81, n. 198, p. 229-243, maio./ago. 2000.

FELIX, Andreza A.; SOUZA, Helio M.; RIBEIRO, Sonia B. F. Aspectos epidemiológicos e sociais da doença falciforme. Revista Brasileira de Hematologia e Hemoterapia, v. 32, n. 2, p. 203-208, 2010.

FERNANDES, Priscila, A ; FICARELLI, Valéria, F ; MOREIRA, Gisele, F ; NETO, Luigi, M. Aspectos fisiológicos da atividade física em portadores de Doença Falciforme. 2002

MAIA, Viviane Q .de O., et al. Conhecimento de educadores sobre doença falciforme nas escolas públicas de Montes Claros - MG. Revista Medica Minas Gerais. 2013; 23 (3): 290296290. 